\title{
Tradução e transferência ${ }^{1}$
}

\author{
Itamar Even-Zohar ${ }^{*}$ \\ Tradução por Juliana Steil ${ }^{* *}$
}

\begin{abstract}
RESUMO: O ponto central deste trabalho, apresentado originalmente em um evento na Universidade de Tel Aviv em 1978 e revisado em outras oportunidades (Even-Zohar, 1981; 1990), foi um convite ao desenvolvimento da pesquisa em tradução dentro do contexto mais abrangente da "transferência". O artigo argumenta, nesse sentido, que a atividade de traduzir é uma restrição fundamental de natureza sistêmica, um fator integrante da transferência, e propõe, ao final, uma lei geral da tradução.
\end{abstract}

Palavras-chave: teoria da transferência; teoria da tradução; polissistemas.

Nosso conhecimento acumulado sobre a tradução cada vez mais indica que os procedimentos tradutórios entre dois sistemas (sociedades/línguas/literaturas) são em princípio análogos, até mesmo homólogos, a transferências dentro das fronteiras do sistema. A hipótese da analogia/homologia já foi formulada antes, notavelmente por Jakobson (1959), mas as suas consequências para a teoria da tradução não chegaram a ser exploradas. Devemos continuar ignorando esta hipótese? Não seria mais sensato reconhecer a prática implícita pela qual a tradução é discutida em termos de transferência e vice-versa? Em outras palavras, não seria produtivo pensar e trabalhar explicitamente, em vez de implicitamente, a partir de uma teoria da transferência? Em caso positivo, onde estaria localizada a tradução inter-sistêmica, e quais seriam as consequências?

Cedo ou tarde, acredito, passará a ser antieconômico tratar da transferência e da tradução separadamente. Quando, por exemplo, afirmamos em teoria da tradução que sob determinadas circunstâncias é mais provável que modelos secundários estejam operando por causa da posição periférica da literatura traduzida (no polissistema literário) e que é mais frequente as periferias utilizarem modelos secundários, já estamos ultrapassando a questão da "tradução" propriamente dita para tratar de potencialidades da transferência intersistêmica. Em apreço a jogos terminológicos, poderíamos facilmente dizer que a secundarização está obviamente envolvida com os procedimentos tradutórios enquanto, de outro lado, a tradução geralmente envolve a secundarização. Sutilezas retóricas à parte, esta formulação, embora esclarecedora, não é muito satisfatória. Não por ela não indicar nenhuma hipótese válida, mas porque ela apresenta um processo complexo, no qual aspectos (ou procedimentos) ocorrem de modo interdependente e simultâneo, como se fossem dois fenômenos discretos pertencentes, por assim dizer, a duas esferas diferentes.

A falta de uma teoria da transferência explicitamente formulada cria, assim, os seguintes resultados: (a) Um corpo de fenômenos homólogo a outro é tratado como objeto de estudo enquanto este outro não é reconhecido como tal, sendo abordado casualmente, como se pertencesse a um conjunto semiótico totalmente diferente; (b) procedimentos gerais, válidos para vários co-sistemas, são considerados particulares, ou seja, pertencentes a apenas um corpo oficialmente reconhecido. Isso não apenas sugere perspectivas exageradas, mas dificulta a descoberta do que - uma vez esclarecidos os procedimentos gerais - realmente são os procedimentos particulares.

De outro lado, há sempre o risco de excesso de generalizações, e se uma teoria da transferência fosse substituir por completo a teoria da tradução, um corpo relativamente sólido de questões estaria perdido. Pode-se argumentar que talvez seja melhor, então, manter nossa teoria reduzida, sabendo que não é adequada? De todo modo, estou convencido de que, em nosso estágio atual da teoria da tradução, simplesmente não temos 
muita escolha. Isto se queremos prosseguir com o que já foi aceito como "novos rumos" nos estudos da tradução, onde as questões de transferência são tratadas na prática como inseparáveis das questões de tradução ${ }^{2}$.

Algumas pessoas tomariam isto como uma proposta para liquidar os estudos da tradução. Penso que a conclusão vai na direção oposta: com um contexto mais amplo, ficará ainda mais claro que a "tradução" não é um procedimento marginal dos sistemas culturais. Em segundo lugar, o contexto mais amplo nos ajuda a identificar o que é de fato particular na tradução. Em terceiro lugar, ele mudará nossa concepção do texto traduzido de maneira que possamos talvez nos libertar de determinados critérios postulados. E, em quarto lugar, pode nos ajudar a isolar a natureza dos "procedimentos tradutórios".

Gostaria de discutir em mais detalhe os pontos terceiro e quarto. Nossa prática referente aos produtos da tradução tem sido um tanto seletiva e, em última análise, inconsistente do ponto de vista teórico. Em nome de uma teoria pura, aceitamos, de um lado, o fato de a tradução envolver a reformulação de um enunciado fonte por meio de um enunciado alvo. Assim, admitiu-se que o processo de decomposição e recomposição era de natureza tradutória. De outro lado, contudo, quando o resultado desta relação não obedecia as normas pré-postuladas formuladas pela cultura em questão (e aceita num nível abstrado pela teoria da tradução como um critério de seleção), o produto de tal relação não era considerado uma tradução, mas outra coisa - "adaptação", "imitação" -, sendo excluído do domínio da teoria da tradução. A consequência disso foi uma tal quantidade de "não traduções" que, se fôssemos fazer as contas, veríamos que a maioria dos produtos da transferência interlingual ficaria fora do escopo da teoria da tradução. Embora tenha servido, reconhecidamente, para elaborar sólidos conceitos fundamentais para discutir a tradução, esta visão não pode mais ser sustentada. Isto porque tal visão isola textos traduzidos de muitos outros tipos de textos, em vez de colocar os primeiros no contexto destes últimos.

Se então reconhecermos todos os produtos da transferência interlingual como relevantes para a tradução, chegaremos a duas conclusões:

(1) O problema da traduzibilidade deve ser reformulado. "Descobrir" que a probabilidade de um enunciado traduzido ser idêntico ao seu original é sempre menor não tem muita relevância. Parece ser mais produtivo saber sob quais circunstâncias, e de que modo em particular, um enunciado/texto alvo b se relaciona (ou é relacionável) com um enunciado/texto fonte a.

(2) Uma vez que os procedimentos tradutórios produzem produtos específicos em um sistema alvo, e já que estes estão, em tese, envolvidos com processos (e procedimentos) em geral, não há motivo para limitar as relações tradutórias apenas a textos em si. Textos considerados competentes, ou seja, modelos, são claramente um fator central na tradução, porque são componentes do sistema (o repertório de opções disponíveis). Ao não perceberem isso, as teorias da tradução (assim como a maior parte das teorias da literatura) deixaram de observar - para mencionar apenas um exemplo - o intrincado processo pelo qual um texto específico é traduzido de acordo com os modelos do sistema alvo domesticados pela apropriação do modelo e realizados com procedimentos de natureza tradutória. Até agora, apenas as traduções de texto propriamente dito foram aceitas como fonte legítima para a exploração teórica, enquanto o complexo problema da interferência sistêmica, pela qual itens do repertório (incluindo, claro, modelos) são transplantados de um sistema a outro, tem sido ignorado. Do ponto de vista da teoria dos polissistemas, ou da teoria geral da transferência defendida, não faz sentido considerar a penetração de um sistema A em um sistema B como "influência" e considerar a reformulação de textos pertencentes ao mesmo sistema A pelo sistema B como "tradução". 
Retornemos ao quarto ponto, isto é, à pergunta "O que significam procedimentos tradutórios?"

Por incrível que pareça, a noção de traducionalidade não é nada clara na teoria da tradução. Muito esforço foi investido na descrição das respectivas possibilidades e preferências na tradução interlingual. Mas mesmo a análise mais minuciosa nesse sentido não poderia explicar o real comportamento da tradução sob várias circunstâncias. Por exemplo, quando determinada função presente no sistema $\mathrm{A}$ acontece de faltar no sistema B, pode-se explicar a razão de ela não aparecer no texto na língua B quando ele é um texto alvo. Mas quando, apesar de sua existência no sistema alvo, ela não aparece no texto alvo, ou, apesar de sua inexistência, ela aparece (como resultado de uma interferência), não é possível apresentar uma explicação. Sem dúvida, uma análise contrastiva por si, especialmente se realizada apenas no nível da linguagem, explicará somente as alternativas possíveis à tradução no nível da operação linguística pronta (escolhas e decisões). Mas se o objetivo for descobrir quais restrições podem ter produzido determinado comportamento/produto, é necessário descobrir as relações hierárquicas entre os vários fatores, assim como reconhecer que sob determinadas circunstâncias podem operar restrições não apenas na seleção feita a partir de alternativas estabelecidas, mas também na produção de alternativas que não existiam antes. É apenas quando os sistemas são considerados homogêneos, estáticos e fechados que uma tal compreensão não poderá ser alcançada.

O que sabemos então sobre hierarquia de restrições, e quais fatores podem funcionar como tais? Para começar, realmente concordamos com a ideia de restrição? Por exemplo, a estrutura da língua deve ser tratada como uma restrição, ou seria mais econômico do ponto de vista teórico levar em conta apenas os fatores que operam quando várias alternativas estão disponíveis?

Seja qual for a resposta a estas perguntas, parece claro que não se comprova que os chamados "níveis inferiores" de um sistema alvo são restrições mais fortes do que os "níveis superiores". Assim, uma ordem de palavras padronizada, um modelo linguístico, não será necessariamente mais forte que, digamos, um modelo de réplica num romance, se determinados aspectos neutralizam o "padrão" de ordem de palavras e impõem regras diferentes.

No texto literário (mas não apenas nele), as funções literárias podem neutralizar as funções linguísticas padronizadas e substituí-las por funções não padronizadas, se não houver mecanismo de rejeição que impeça isto. Estes fenômenos não podem mais ser desprezados como "violação" da língua ou "mau comportamento": eles estão lá, e podem inclusive constituir o princípio central de processamento de determinado tipo de textos. Nesse sentido, a "língua" pode ter mudado sob a pressão de tais fenômenos e não o contrário. Quando se observa a multidão de casos que não são explicados com base ou em fatores de decisão "baixos" ou "locais", deve-se admitir que modelos globais, sejam explicitamente formulados ou implicitamente incorporados, provavelmente pesam mais sobre o comportamento tradutório e, por isso, explicam melhor as características do texto alvo.

Então como podemos conceber os procedimentos tradutórios? O "tradutório" deve ser entendido como o princípio da transferência, sendo o comportamento e o resultado dele determinados pelas relações entre fonte e alvo, que não é "por si próprio"? Se for assim, significa que, com exceção deste princípio, todo o restante da teoria da tradução consiste de remendos da teoria da interferência, da linguística contrastiva, ou da semiótica, etc?

Posso pensar em duas respostas a estas perguntas. 
Em primeiro lugar, o fato de a maior parte das hipóteses da teoria da tradução ser emprestada de outros ramos, como a teoria da interferência, ou a poética contrastiva (se é que esta disciplina existe), não significa termos de aceitar agora o que rejeitamos por tanto tempo, a saber, que não existem os estudos da tradução como disciplina autônoma. $\mathrm{O}$ caráter eclético de muitas das teorias da tradução resultou não do fato mencionado, mas do fato de que as várias hipóteses não foram submetidas a nenhuma hipótese sobre o princípio da tradução. Por isso, não foi possível fazer qualquer conjectura sobre qualquer das funções envolvidas. Porém, uma vez entendida a tradução como um princípio sistêmico específico, ou seja, um parâmetro de manipulação sistêmica - ou de processamento sistêmico -, o conglomerado de disciplinas torna-se uma disciplina separada.

Em segundo lugar, a traducionalidade não é apenas um princípio de processamento cujos resultados são determinados pelas restrições semióticas em operação no nível sistêmico/inter-sistêmico. É também um processo geral que produz os seus resultados por sua própria natureza. Em trabalho anterior (Even-Zohar, 1971), defendi que podemos encontrar na tradução padrões que são inexplicáveis nos termos dos repertórios envolvidos. É a própria atividade de traduzir que direciona o indivíduo a tomar determinadas decisões. Esta atividade deve, assim, ser reconhecida como uma restrição fundamental de natureza sistêmica, um fator integrante da transferência. Na teoria da transferência, este princípio será então considerado um procedimento básico que (devido à decomposição/recomposição inevitavelmente envolvida nele) processa os enunciados/textos de modo a se comportarem de maneira diferente de sua fonte. Naturalmente, este procedimento é necessário para explicar o mais básico princípio de processamento para um alvo. Supõe-se que as especificidades deste processamento sejam determinadas pela hierarquia das restrições semióticas, sendo as mais fortes aquelas porções do repertório promovidas pelas relações dominantes dentro do polissistema alvo.

Em vista do sugerido anteriormente, é possível propor uma lei geral da tradução:

\begin{abstract}
Num sistema alvo B, existente dentro do mesmo polissistema ou em um polissistema diferente - dependendo de estar ele em crise ou de ser forte ou fraco, diante do sistema A - um texto alvo b será produzido de acordo com procedimentos de transferência e com as restrições impostas a estes procedimentos pelas relações internas do polissistema alvo, sendo que os procedimentos e as restrições governam e são governados pelo repertório de funções existentes e não existentes do polissistema alvo ${ }^{3}$.
\end{abstract}

\title{
Pós-escrito (2018)
}

A primeira versão deste artigo foi apresentada no simpósio internacional "Teoria da Tradução e Relações Interculturais", realizado na Universidade de Tel Aviv em 28-31 de março de 1978, sendo posteriormente publicada em Even-Zohar (1981); mais tarde, o artigo foi revisado e publicado em Even-Zohar (1990). O ponto central deste artigo foi um convite ao desenvolvimento da pesquisa em tradução dentro de um contexto mais amplo e significativo, que sugeri chamar de "transferência". Passaram-se quarenta anos desde o meu "convite", período em que os Estudos da Tradução de fato se tornaram uma disciplina mais robusta e amplamente reconhecida, com uma série de novas direções. A ligação entre a tradução e a transferência tem sido estudada e discutida em muitos trabalhos, em várias áreas e em diferentes disciplinas. Uma rápida busca no Google Acadêmico para a expressão "translation and transfer" mostra mais de três milhões de publicações, muitas das quais são bastante pertinentes. No âmbito dos Estudos da Tradução, publicações importantes como os Handbooks of Translation Studies, editados por Gambier \& Doorslaer (2010) e por Millán \& Bartrina (2013), dedicam uma entrada a "Transferência e Estudos da 
Transferência" (Göpferich, 2010), ou apresentam referências aos vários aspectos da transferência. Todas estas ricas e multifacetadas publicações são um claro testemunho da profunda necessidade que havia de uma melhor compreensão dos processos de transferência que se aceleraram extraordinariamente no mundo globalizado moderno. $\mathrm{O}$ presente cenário internacional mostra, assim, uma vitalidade acadêmica de fato promissora.

Itamar Even-Zohar

Dezembro de 2018

\title{
Translation and transfer
}

\begin{abstract}
The main gist of this paper, whose first version was presented in a symposium held at the Tel Aviv University in 1978 and later revised (Even-Zohar, 1981; 1990), was a call for developing translation research within the larger context of "transfer." In these terms, the present paper argues that the activity of translating is a fundamental constraint of systemic nature, an integral factor of transfer, and finally, it proposes a comprehensive law of translation.
\end{abstract}

Keywords: transfer theory; translation theory; polysystems.

\footnotetext{
${ }^{1}$ Texto originalmente publicado em Polysystem Studies [=Poetics Today 11:1 (1990)], pp. 73-78. Nosso imenso agradecimento ao Professor Itamar Even-Zohar, que autorizou a presente tradução.

* Unidade de Pesquisa da Cultura, Universidade de Tel Aviv

** Universidade Federal de Pelotas

2 Estes "novos rumos" (expressos e descritos, por exemplo, em Holmes et al., 1978; Even-Zohar \& Toury, 1981; Hermans, 1985) envolvem a aceitação da estratificação polissistêmica como relevante para o comportamento tradutório, suas implicações para as relações entre repertórios gerais e tradutórios, a prioridade do estado do sistema da Literatura Alvo como restrição para o comportamento tradutório em relação ao estado do sistema da Literatura Fonte. Em suma, fortes hipóteses que ganharam certo apoio de um grupo relativamente grande de pesquisadores da tradução.

3 Ver discussão sobre a oposição fraco-forte em "Leis da interferência literária" e "A interferência em polissistemas literários dependentes”. Um exemplo da possível lei que governa as relações entre a oposição fraco-forte e a existência vs. não existência do repertório pode ser o seguinte: se um polissistema alvo é fraco diante de um polissistema fonte, então as funções não existentes podem ser domesticadas, possibilitando, assim, uma relacionabilidade mais alta (entre Alvo e Fonte) desde que a posição do sistema traduzido dentro do polissistema alvo seja central.
}

\section{REFERÊNCIAS}

EVEN-ZOHAR, Itamar. Translation Theory Today: A Call for Transfer Theory. In: EVENZOHAR, Itamar \& Gideon Toury (eds.). Translation Theory and Intercultural Relations [=Poetics Today, Vol. 2: 4]. Durham NC: Duke University Press, 1981, pp. 1-7.

EVEN-ZOHAR, Itamar. Translation and Transfer. In: Polysystem Studies. [=Poetics Today 11:1], 1990, pp. 73-78.

GAMBIER, Yves \& Luc Van Doorslaer (eds.). Handbook of Translation Studies. 4 vols Vol. I. Amsterdam \& Philadelphia: John Benjamins, 2010.

GÖPFERICH, Susanne. Transfer and Transfer Studies. In: GAMBIER, Yves \& Luc Van Doorslaer (eds.). Handbook of Translation Studies. Amsterdam \& Philadelphia: John Benjamins, 2010, pp. 374-377. 
MILLÁN, Carmen \& Francesca Bartrina. The Routledge Handbook of Translation Studies. [=Routledge Handbooks in Applied Linguistics]. Abingdon \& New York: Taylor \& Francis, 2013. 